Graduate Institute of

International and Development Studies Working Paper

No: $02 / 2013$

\title{
Finance and Economic Development in a Model with Credit Rationing
}

\author{
Jean-Louis Arcand \\ Graduate Institute of International and Development Studies \\ Enrico Berkes \\ Northwestern University \\ Ugo Panizza \\ Graduate Institute of International and Development Studies
}

\begin{abstract}
This paper develops a simple model with credit rationing and endogenous default risk in which the expectation of a bailout may lead to a financial sector which is too large with respect to the the social optimum. The paper concludes with a short discussion of how this model could be used as a building block for models aimed at endogenizing the probability of a bailout, and discussing the relationship between the size of the financial sector and economic growth in the presence of default risk.
\end{abstract}

(C) The Authors.

All rights reserved. No part of this paper may be reproduced without the permission of the authors. 


\title{
Finance and Economic Development in a Model with Credit Rationing
}

\author{
Jean-Louis Arcand Enrico Berkes Ugo Panizza
}

January $2013^{*}$

\begin{abstract}
This paper develops a simple model with credit rationing and endogenous default risk in which the expectation of a bailout may lead to a financial sector which is too large with respect to the the social optimum. The paper concludes with a short discussion of how this model could be used as a building block for models aimed at endogenizing the probability of a bailout, and discussing the relationship between the size of the finanancial sector and economic growth in the presence of default risk.
\end{abstract}

\section{Introduction}

Bagehot (1873) and Schumpeter (1911) were among the first to point out that finance plays a key role for economic development. Empirical work by Goldsmith (1969) confirmed the presence of a correlation between finance and economic development but could not establish whether the link between these two variables was causal. Successive work by King and Levine (1993), Levine, Loayza, and Beck (2000), Beck, Levine, and Loayza (2000), and Rajan and Zingales (1998) provided convincing evidence that financial development has a causal effect on economic growth. There is now an enormous literature showing that finance does indeed play a positive role in promoting economic development and, while recent research has shown that not all types of credit are the same (with enterprise credit being the driver of growth, Beck et al., 2008), most economists now believe in such a causal link (Levine, 2005). ${ }^{1}$

It is however possible that there is a threshold above which finance starts having negative returns and that the current crisis was caused by financial sectors which were "too large"

*Arcand is with the Graduate Institute, Geneva, Berkes with Northwestern University, and Panizza with the Graduate Institute, Geneva. Email: jean-louis.arcand@graduateinstitute.ch, enrico.berkes@u.northwestern.edu, ugo.panizza@graduateinstitute.ch. The views expressed in this paper are the authors' only and need not reflect, and should not be represented as, the views of any of the institutions that the authors are affiliated with.

${ }^{1}$ There are, however, also papers that challenge this view (for a review see Panizza, 2012). 
compared to the size of the domestic economy. Proponents of this view include Martin Wolf who noted that there might be something wrong with a situation in which "instead of being a servant, finance had become the economy's master" (Wolf, 2009), two former chief economists of the IMF (Rajan, 2005, and Johnson, 2009) who wrote influential articles on the potential dangers of large financial sectors, and a recent World Bank report (De La Torre et al., 2011). Along similar lines, Tobin (1984) suggested that a large financial sector may lead to a suboptimal allocation of talents and to private returns that are much larger than social returns (for evidence in this direction see Philippon and Reshef, 2008). In Arcand et al. (2012) we show that these claims have an empirical backing and that the marginal effect of financial development on economic growth becomes negative when credit to the private sector reaches 100 percent of GDP. In that paper, we show that our results are not only driven by volatility, banking crises or poor institutions.

In a simple model without credit rationing and with exogenous probability of default, it is easy to show that the presence of a bank bailout will generate a level of credit that is greater than the social optimum. In this paper, we show that the same result applies when we allow for credit rationing and endogenize the probability of default. A paper which is closely related to our work is De Gregorio and Guidotti (1995) who develop a model in which the presence of a government bailout and a poor regulatory framework lead to suboptimal screening and excessive lending.

\section{The Economics 101 Model}

We set the stage with the simplest textbook model. Consider an economy in which entrepreneurs who cannot post collateral produce by borrowing from competitive banks which, in turn, borrow abroad at an exogenous interest rate $R$ and lend at a rate $r \geq R$. In such a setup, the capital stock $K$ is equal to the size of the financial sector. Entrepreneurs are successful with probability $\pi$ and unsuccessful with probability $1-\pi$. The representative entrepreneur has the following production function:

$$
Y=\left\{\begin{array}{cl}
A F(K) & \text { with probability } \pi \\
\delta K & \text { with probability }(1-\pi)
\end{array}\right.
$$

with $F^{\prime}>0, F^{\prime \prime}<0$ and $\delta<(1+R)$ (i.e., failed projects have negative residual value). ${ }^{2}$

A social planner interested in maximizing the country's value added $V=\pi A F(K)+(1-$ $\pi) \delta K-(1+R) K$ would choose the level of capital that satisfies the first order condition:

$$
F^{\prime}\left(K^{S P}\right)=\frac{(1+R)-(1-\pi) \delta}{\pi A} .
$$

Let us now consider the decentralized equilibrium. When the project is successful, banks are paid back in full and get $(1+r) K$. When the project is not successful, they receive the residual value of the project and potentially a bailout: $(1+\gamma) \delta K(\gamma \geq 0$ is the bailout;

\footnotetext{
${ }^{2}$ The results would not change if the production function were to include labor, with perfectly inelastic labor supply.
} 
we assume that $(1+\gamma) \delta K \leq(1+r) K) \cdot{ }^{3}$ Competitive banks choose the interest rate that satisfies the zero-profit condition $(1+r) \pi+(1-\pi)(1+\gamma) \delta=(1+R)$, yielding:

$$
r=\frac{(1+R)-(1-\pi)(1+\gamma) \delta-\pi}{\pi}
$$

Given limited liability, a firm's expected profits are given by $P=\pi[A F(K)-(1+r) K]$, with FOC $F^{\prime}=\frac{(1+r)}{A}$. Using (3), we obtain:

$$
F^{\prime}\left(K^{*}\right)=\frac{(1+R)-(1-\pi)(1+\gamma) \delta}{A \pi}
$$

Without distortions (i.e., with $\gamma=0$ ), the decentralized equilibrium is equal to the social optimum (with $\gamma=0, F^{\prime}\left(K^{*}\right)=F^{\prime}\left(K^{S P}\right)$ ). In the presence of a bailout $(\gamma>0)$, we find that the capital stock (and total credit) in the decentralized equilibrium is larger than the socially optimal level of capital.

\section{The Credit Rationing Model}

We now check whether the Economics 101 result can be replicated in a model with credit rationing and endogenous default probability. In particular, we consider a simple economy where production takes place in two sectors, and where individuals supply labor inelastically and never save.

Given our zero saving assumption, firms finance investment by borrowing abroad at the exogenous interest rate $R$ (as in the Economics 101 model). The only role of the competitive financial sector is to screen projects and use its screening technology to intermediate foreign loans. ${ }^{4}$

We assume that the economy consists of two sectors. The first sector is composed of a large number of established competitive firms with a standard constant returns to scale technology: $y_{c}=F(K, L)$ (with $F_{K}>0, F_{L}>0, F_{K K}<0$ and $F_{L L}<0$ ). As output is non-stochastic, we assume that established firms can post collateral, guaranteeing that they will always repay their loans. Since loans to these firms carry no risk, the competitive banking sector will charge them an interest rate $r_{c}=R$ (with $F_{K}=r_{c}$, and $F_{L}=w$; where $w$ is the wage rate). At this stage, the only reason for introducing this sector is to generate resources for the bailout. In the concluding section, we also discuss how the second sector could be used to build a model that links the size of the financial sector to economic growth.

Next, we build on Stiglitz and Weiss's (1981) credit rationing model and assume that the second sector is composed of monopolistic new entrants with the following stochastic production function:

$$
y=\theta \sqrt{D}
$$

\footnotetext{
${ }^{3}$ In the next section we also allow for imperfect creditor rights and discuss what happens when $\gamma$ is negative.

${ }^{4}$ We rule out any concerns related to the behavior of the exchange rate by assuming a common currency. We also assume, without loss of generality, no cost associated with screening projects.
} 
where $D$ is the firm's stock of debt and $\theta$ is a random variable distributed according to the uniform density over $[0, N] .{ }^{5}$ Given stochastic production, loans to firms in this sector are risky and the banks will charge an interest rate $r>R$.

Total production is given by $Y=y_{c}+y$ and GNP is equal to $Y-(1+R)(K+D)$, where $K+D$ is the size of the financial sector.

\subsection{Social Planner}

The optimal size of the financial sector is equal to the level of investment that maximizes domestic value added. Since the contribution to domestic value added of the traditional sector is fully determined by the exogenous labor supply and foreign interest rate, we only consider the innovative sector. The social planner's problem is:

$$
\max _{\{D\}} \frac{1}{N} \int_{0}^{N} \theta \sqrt{D} d \theta-(1+R) D .
$$

The solution to this problem yields a level of debt and investment that maximizes social welfare, and which is equal to:

$$
D^{* *}=\frac{N^{2}}{16(1+R)^{2}} .
$$

The optimal level of debt is a negative function of the cost of funds $R$, and a positive function of productivity which, in turn, is determined by the upper bound of the distribution of $\theta$.

\subsection{Decentralized Equilibrium}

Because of limited liability and the assumption that entrepreneurs have no equity capital, the profit of the representative entrepreneur is given by: $\pi=\max [\theta \sqrt{D}-(1+r) D, 0]$. Given the uniform distribution of $\theta$, this yields an expected profit of:

$$
E(\pi)=\frac{1}{N} \int_{\theta^{*}}^{N}[\theta \sqrt{D}-(1+r) D] d \theta
$$

where $\theta^{*}=(1+r) \sqrt{D}$ is the threshold level of the realization of the random variable above which the entrepreneur makes positive profits and is able to repay the loan. Performing the integration we obtain:

$$
E(\pi)=\frac{\sqrt{D}}{2 N}[(1+r) \sqrt{D}-N]^{2} .
$$

In order to use equation (9) to find the level of debt that maximizes profit, we need to solve for the endogenous lending rate $r$. Given our assumption of a competitive banking system, this is the rate that equates a lender's expected profits, $E(L)$, to zero.

\footnotetext{
${ }^{5}$ We choose a specific functional form because it is impossible to obtain a closed-form solution with a generic production function.
} 
$E(L)$ is composed of three elements: (i) full debt repayment times the probability that the project will be successful; (ii) the recovery value times the probability that the investment will be unsuccessful; and (iii) the cost of funds. Formally:

$$
\begin{aligned}
E(L)= & \frac{1}{N} \int_{\theta^{*}}^{N}(1+r) D d \theta+ \\
& +\frac{1}{N} \int_{0}^{\theta^{*}}[\theta \sqrt{D}+\gamma((1+r) D-\theta \sqrt{D})] d \theta-(1+R) D
\end{aligned}
$$

The term in the first integral is the repayment if the investment is successful, while the term in the second integral measures what the lenders will recover in case of default; the third term in equation (10) is the cost of lending. If $\gamma \neq 0$, the recovery value in case of default is different from the residual value of the defaulted project. As in the Economics 101 model, the parameter $\gamma$ is crucial in our story because it introduces a wedge between the socially optimal level of debt and the market equilibrium. We will show that when $\gamma<0$ the financial system is too small with respect to the social optimum and when $\gamma>0$ the financial system is too big with respect to the social optimum.

We can think of $\gamma$ as a combination of the strength of creditors' rights $(c)$ and government bailout $(b)$ in case of default. To fix ideas, assume that $\gamma=(c+b-1)$, with $0 \leq c \leq 1$ and $0 \leq b<2 .{ }^{6}$ In this setting, $c=1$ denotes a situation with perfect creditor rights (lenders can recover the whole residual value of the failed investment project) and $c<1$ denotes a situation in which lenders can only recover a fraction of the failed investment project. Similarly, $b=0$ denotes a situation in which the government never bails out lenders, and $b>0$ denotes a situation in which the government offers a (possibly partial) bailout. We assume that the bailout is financed with a lump-sum tax on the first sector.

Consider, for instance, the case of a country with no creditor rights and no bailout. In this case, creditors will receive no payments in case of default: $(\theta \sqrt{D}+\gamma[(1+r) D-\theta \sqrt{D}])=0$ and $\gamma=-\frac{\theta \sqrt{D}}{(1+r) D-\theta \sqrt{D}}<0$. With perfect creditor rights $(c=1)$ and no bailout $(b=0)$, instead, we get $\gamma=0$, and the bank will receive all the residual value of the failed investment project (i.e., $\theta \sqrt{D})$. Note that the presence of a positive bailout $(b>0)$ is a necessary but not sufficient condition for $\gamma>0$. With a positive bailout $(b>0)$, creditors could receive either less than the recovery value (if $b<1-c$ ) or more than the recovery value (if $b>1-c$ ).

Performing the integration in equation (10), we obtain:

$$
E(L)=\frac{D\left[2 N(r-R)+(1+r)^{2}(\gamma-1) \sqrt{D}\right]}{2 N} .
$$

Competitive lenders will choose the interest rate that sets expected profits equal to zero. Equation (11) is a quadratic in $r$ and admits two solutions:

$$
r_{1}^{*}=\frac{N+\sqrt{\psi}}{\sqrt{D}(1-\gamma)}-1 ; \quad r_{2}^{*}=\frac{N-\sqrt{\psi}}{\sqrt{D}(1-\gamma)}-1,
$$

\footnotetext{
${ }^{6}$ In order to avoid negative payments or payments which are greater than the original loan, it is also necessary to impose a joint constraint on $c$ and $b$ such that their sum guarantees that $-\frac{\theta \sqrt{D}}{(1+r) D-\theta \sqrt{D}} \leq \gamma<1$. Note that in case of default the denominator of the lower bound is always positive and $-\frac{\theta \sqrt{D}}{(1+r) D-\theta \sqrt{D}}>-1$.
} 
where $\psi=N[N-2 \sqrt{D}(1+R)(1-\gamma)]$. For the time being we will assume that $\psi>0$ : we will later show that this condition holds in practice. ${ }^{7}$ With $\psi>0$ it is always true that $r_{1}^{*}>r_{2}^{*}$.

Since lenders are indifferent between interest rates (they always make zero profits), we pick the one that makes the borrower better off (any lender who charges a different interest rate would lose all customers). By substituting the expressions in (12) into (9) we obtain:

$$
E\left(\pi_{1}\right)=\sqrt{D} \frac{[\sqrt{\psi}+N \gamma]^{2}}{2 N(\gamma-1)^{2}} ; \quad E\left(\pi_{2}\right)=\sqrt{D} \frac{[\sqrt{\psi}-N \gamma]^{2}}{2 N(\gamma-1)^{2}}
$$

Since $\psi>0, E\left(\pi_{1}\right)>E\left(\pi_{2}\right)$ if $\gamma>0$ and $E\left(\pi_{1}\right)<E\left(\pi_{2}\right)$ if $\gamma<0$ (if $\left.\gamma=0, E\left(\pi_{1}\right)=E\left(\pi_{2}\right)\right)$. Whenever $\gamma>0$, borrowers will prefer the higher interest rate and when $\gamma<0$ borrowers will prefer the lower interest rate. The intuition for this is simple: inspection of equation (9) reveals that $E(\pi)$ is quadratic (and $U$-shaped) in $r$. It is therefore not surprising that a higher level of the interest rate is entirely compatible with higher borrower welfare. ${ }^{8}$

We can now maximize $E\left(\pi_{1}\right)$ and $E\left(\pi_{2}\right)$ with respect to $D$ and solve for the optimal amount of debt. Let us start with the case in which $\gamma>0$ and expected profits are given by $E\left(\pi_{1}\right)$. In this case, the FOC is given by:

$$
\frac{\partial E\left(\pi_{1}\right)}{\partial D}=\frac{[\sqrt{\psi}+N \gamma][N-4 \sqrt{D}(1+R)(1-\gamma)+\gamma \sqrt{\psi}]}{4 \sqrt{D} \sqrt{\psi}(\gamma-1)^{2}}=0
$$

Given our previous assumptions, when $\gamma>0$, the first term in square brackets in the numerator and the denominator of (14) are both always positive. Therefore, we can find the optimal value of $D$ by setting the second term in square brackets in the numerator equal to zero. This yields two solutions:

$$
D_{11}^{*}=\frac{N^{2}\left[8+\gamma^{4}-\gamma\left(4-\gamma^{2}\right) \sqrt{8+\gamma^{2}}\right]}{128(1+R)^{2}(\gamma-1)^{2}} ; \quad D_{12}^{*}=\frac{N^{2}\left[8+\gamma^{4}+\gamma\left(4-\gamma^{2}\right) \sqrt{8+\gamma^{2}}\right]}{128(1+R)^{2}(\gamma-1)^{2}} .
$$

Since $0<\gamma<1, \gamma\left(4-\gamma^{2}\right)>0$, and $D_{12}^{*}>D_{11}^{*}$.

At this point, we can substitute $D_{11}^{*}$ and $D_{12}^{*}$ into $\psi$ and, after some tedious algebra, show that they satisfy the condition that $\psi>0$. It is also easy to show that $\frac{\partial^{2} E\left(\pi_{1}\right)}{\partial D^{2}}<0$ and therefore that our solution satisfies the second order condition for a maximum. ${ }^{9}$ The appendix shows that when $\gamma>0$, expected profits are always higher with $D_{12}^{*}$ and therefore the borrower always prefers the solution with a higher level of credit.

Summing up, with $\gamma=0$ the decentralized equilibrium is equal to the social optimum $\left(D_{11}^{*}=D_{12}^{*}=D^{* *}\right.$ where $D^{* *}$ was given in equation $(7)$ ), but for positive values of $\gamma$, we find

\footnotetext{
${ }^{7}$ Assuming that $\gamma<1$ is necessary to guarantee that the denominators in the interest rate equations are nonzero.

${ }^{8}$ In turn, the $U$-shape of $E(\pi)$ in (9) stems from the linearity in $\theta$ of the integrand in equation (8), combined with the limited liability assumption.

${ }^{9}$ Let $A=[\sqrt{\psi}+N \gamma] ; \quad B=[\psi / N+\gamma \sqrt{\psi}] ;$ and $C=\left(4 \sqrt{D} \sqrt{\psi}(\gamma-1)^{2}\right)$. Then $\frac{\partial^{2} E\left(\pi_{1}\right)}{\partial D^{2}}=$ $\frac{\left(A \frac{\partial B}{\partial D}+B \frac{\partial A}{\partial D}\right) C-\frac{\partial C}{\partial D} A B}{C^{2}}$. Given that at $D^{*}, B$ is equal to zero, the SOC simplifies to $\frac{\partial^{2} E\left(\pi_{1}\right)}{\partial D^{2}}=\frac{A}{C} \frac{\partial B}{\partial D}$. Since $A>0, C>0$, and $\frac{\partial B}{\partial D}<0$, we get that $\frac{\partial^{2} E\left(\pi_{1}\right)}{\partial D^{2}}<0$.
} 
that credit is always above the social optimum $\left(D_{12}^{*}>D^{* *}\right)$. The presence of a bailout leads to too much risk taking and to a financial sector which is larger than the social optimum (this does not necessarily mean that bailouts are never desirable, more on this below).

We now consider the case with $\gamma<0$. In this case, $E\left(\pi_{2}\right)>E\left(\pi_{1}\right)$ and the borrowers will choose the lower interest rate $r_{2}^{*}$. Taking the first order condition, we obtain:

$$
\frac{\partial E\left(\pi_{2}\right)}{\partial D}=\frac{[\sqrt{\psi}-N \gamma][N-4 \sqrt{D}(1+R)(1-\gamma)-\gamma \sqrt{\psi}]}{4 \sqrt{D} \sqrt{\psi}(\gamma-1)^{2}}=0
$$

Since $\gamma<0$, the first expression in square brackets in the numerator is always positive (and so is the denominator). We can thus find that value of $D$ that maximizes profits by setting the second term in the numerator equal to zero. As this term is equal to the one considered earlier (in equation (14)), we obtain the same solutions: $D_{21}^{*}=D_{11}^{*}$ and $D_{22}^{*}=D_{12}^{*}$. However, $\gamma$ is now negative and $D_{21}^{*}>D_{22}^{*}$. The Appendix shows that with $\gamma<0$, borrowers always prefer $D_{21}^{*}$ (again, with $\gamma=0$ we get $D_{21}^{*}=D_{22}^{*}=D^{* *}$ ).

We can now use the expressions in (15) to fully describe the size of the financial sector under positive and negative values of $\gamma$.

$$
D^{*}=\left\{\begin{array}{ccc}
\frac{N^{2}\left[8+\gamma^{4}-\gamma\left(4-\gamma^{2}\right) \sqrt{8+\gamma^{2}}\right]}{128(1+R)^{2}(\gamma-1)^{2}} & \text { if } \quad \gamma<0 \\
\frac{N^{2}}{16(1+R)^{2}} & \text { if } \gamma=0 \\
\frac{N^{2}\left[8+\gamma^{4}+\gamma\left(4-\gamma^{2}\right) \sqrt{8+\gamma^{2}}\right]}{128(1+R)^{2}(\gamma-1)^{2}} & \text { if } \quad \gamma>0
\end{array}\right.
$$

It is easy to show that when $\gamma>0$, there is always "too much" finance $\left(D^{*}>D^{* *}\right.$ because $\gamma^{4}+\gamma\left(4-\gamma^{2}\right) \sqrt{8+\gamma^{2}}>0$ and $\left.(\gamma-1)^{2}<1\right)$.

With $\gamma<0$, the comparison between $D^{*}$ and $D^{* *}$ is more complicated because $\gamma$ increases both the numerator and the denominator of $D^{*}\left(\right.$ with $\gamma<0, \gamma^{4}-\gamma\left(4-\gamma^{2}\right) \sqrt{8+\gamma^{2}}>0$ and $\left.(\gamma-1)^{2}>1\right)$. We can however plot the $D^{*} / D^{* *}$ ratio for $\gamma \in[-1,1)$ and show that when $-1 \leq \gamma<0$, it is always true that $D^{*} / D^{* *}<1$ and when $0<\gamma<1$, it is always true that $D^{*} / D^{* *}>1$ (Figure ??). Therefore, when $\gamma<0$, the financial system is always too small with respect to the social optimum $\left(D^{*}<D^{* *}\right)$.

Equation (17) shows that bailouts are not necessarily a bad idea. The optimal bailout rule is $b=1-c$. Only with perfect creditors rights $(c=1)$ are bailouts never desirable. If $c<1$ and the bailout is financed with lump sum taxes, society will be indifferent between setting $b=1-c$ and a reform that improves creditor rights. Improving creditors' rights will be the preferred option only if the bailout is financed with a distortionary tax.

Note, however, that Figure ?? shows that $D^{*} / D^{* *}$ is generally an increasing and convex function of $\gamma$. Thus, for any any pair of $\gamma_{\mathrm{s}}$ with $\left|\gamma_{i}\right|=\left|\gamma_{j}\right|$ and $\gamma_{i}<0, \gamma_{j}>0$, the deviation from the social optimum is always larger when $\gamma$ is positive. Therefore, in the presence of uncertainty on the value of $c$, policymakers should be conservative in offering bailouts because the costs of overshooting are larger than those of undershooting. This result would be strengthened if we were to assume that the bailout is financed with distortionary taxes.

However, it is straightforward to use our model to show that, under certain conditions, a distortionary tax on the second sector can restore the social optimum. In particular, if $\gamma>0$ and $c=1$, a Pigouvian tax equal to the cost of the potential bailout will make entrepreneurs 
Figure 1: The Optimal Level of Debt. This figure plots $D^{*} / D^{* *}$ for $\gamma \in[-1,1)$. It shows that when $\gamma>0, D^{*}$ is always greater than $D^{* *}$ and when $\gamma<0$, it is always true that $D^{*}<D^{* *}$.

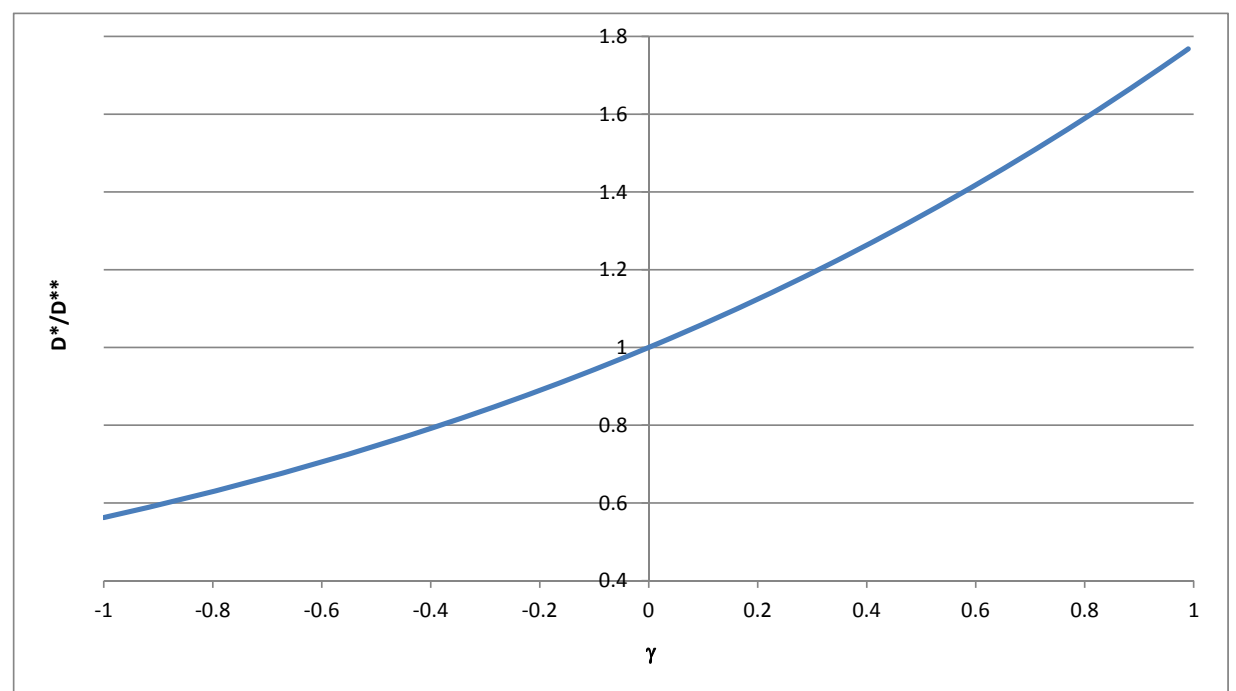


internalize the cost of overborrowing and lead them to choose $D^{* *}$. This is a result similar to that of Jeanne and Korinek's (2010) model of credit booms and busts.

\section{Conclusions}

In this paper we develop a model with endogenous default probability and credit rationing and show that the presence of a bailout leads to a financial system which is "too large" with respect to the social optimum.

Within the model of this paper, there are three factors that determine the size of the financial sector: the productivity parameter $N$, the exogenous interest rate $R$, and the distortion $\gamma$. Therefore, countries with large financial sectors do not necessarily have "too much finance". However, if the size of the financial sector is positively correlated with its political and lobbying power, $\gamma$ could become endogenous, leading to a situation in which countries which have a naturally large financial sector (because of high $N$ ) also end up having too much finance. This is the implicit message of Johnson (2009). We think that the model developed in this paper could serve as a building block for a political economy model aimed at endogenizing $\gamma$.

It is also worth noting that while this paper looks at the relationship between financial development and the level of income, most of the literature concentrates on the relationship between finance and economic growth. While a full dynamic specification is well beyond the scope of this paper, we think that our simple approach could also be used as a building block for a model that describes the relationship between financial development and economic growth. A possible avenue would be to make the number of firms that operate in the traditional sector a function of the number of surviving firms in the innovative sector. In such a setup, policies that maximize the number of surviving firms should also maximize growth. 


\section{References}

[1] Arcand, J.L., Berkes, E. and Panizza, U. (2012), "Too much finance?", IMF working paper, $12 / 161$

[2] Bagehot, W. (1873), Lombard Street: A Description of the Money Market, History of Economic Thought Books, McMaster University Archive for the History of Economic Thought.

[3] Beck, T., Levine, R., and Loayza, N. (2000), "Finance and the sources of growth," Journal of Financial Economics, 58(1-2), 261-300.

[4] Beck, T., Buyukkarabacak, B. Rioja, F, and Valev, N. (2009) "Who Gets the Credit and Does It Matter? Household vs. Firm Lending across Countries" Policy Research Working Paper 4661, The World Bank.

[5] De la Torre, A., Ize, A., and Schmukler, S. (2011) "Financial Development in Latin America and the Caribbean: The Road Ahead" The World Bank, Washington DC.

[6] De Gregorio, J. and Guidotti, P. (1995), "Financial development and economic growth," World Development 23(3), 433-448.

[7] Goldsmith, R. W. (1969), Financial Structure and Development, Yale University Press, New Haven.

[8] Jeanne, O., and Korinek, A. (2010), "Excessive Volatility in Capital Flows: A Pigouvian Taxation Approach," Peterson Institute Working Paper Series WP10-5, Peterson Institute for International Economics.

[9] Johnson, S. (2009), "The quiet coup," The Atlantic (May 2009).

[10] King, R. G. and Levine, R. (1993), "Finance and growth: Schumpeter might be right," The Quarterly Journal of Economics 108(3), 717-37.

[11] Levine, R. (2005), "Finance and growth: Theory and evidence," in Aghion, P. and Durlauf, S., eds, Handbook of Economic Growth, Vol. 1, chapter 12 Elsevier, pp. 865-34

[12] Levine, R., Loayza, N., and Beck, T. (2000), "Financial intermediation and growth: Causality and causes," Journal of Monetary Economics, 46(1), 31-77.

[13] Panizza, U. (2012) "Finance and Economic Development," International Development Policy, p. 141-160

[14] Philippon, T., and Reshef, A. (2008) "Wages and Human Capital in the U.S. Financial Industry: 1909-2006" mimeo, New York University.

[15] Rajan, R. G. and Zingales, L. (1998), "Financial dependence and growth," American Economic Review 88(3), 559-86. 
[16] Rajan, R. G. (2005), "Has financial development made the world riskier?" Proceedings of the 2005 Jackson Hole Conference organized by the Kansas City Fed.

[17] Schumpeter, J. A. (1911), A Theory of Economic Development, Harvard University Press.

[18] Stiglitz, J., Weiss, A. (1981), "Credit Rationing in Markets with Imperfect Information," The American Economic Review 71(3), 393-410.

[19] Tobin, J. (1984), "On the efficiency of the financial system," Lloyds Bank Review 153, $1-15$.

[20] Wolf, M. (2009), "Why dealing with the huge debt overhang is so hard," Financial Times, January 27. 


\section{A Appendix}

\section{A.1 Proof that when $\gamma>0$, the firm will choose $D_{12}^{*}$ (and when $\gamma<0$, the firm will choose $\left.D_{21}^{*}\right)$}

By substitututing $D_{11}^{*}$ and $D_{12}^{*}$ into $E\left(\pi_{1}\right)$, we get:

$$
\begin{aligned}
& E\left(\pi_{1}\left(D_{11}^{*}\right)\right)=\frac{N^{2} \phi_{1}\left(4 \gamma-2 \sqrt{2} \phi_{1}\right)^{2}}{256 \sqrt{2}(1+R)(\gamma-1)^{2}} \\
& E\left(\pi_{1}\left(D_{12}^{*}\right)\right)=\frac{N^{2} \phi_{2}\left(4 \gamma-2 \sqrt{2} \phi_{2}\right)^{2}}{256 \sqrt{2}(1+R)(\gamma-1)^{2}}
\end{aligned}
$$

$\phi_{1}=\sqrt{8+\gamma^{4}-\gamma\left(4-\gamma^{2}\right) \sqrt{8+\gamma^{2}}}$ and $\phi_{2}=\sqrt{8+\gamma^{4}+\gamma\left(4-\gamma^{2}\right) \sqrt{8+\gamma^{2}}}$. Considering the positive roots, we have $\operatorname{sign}\left(\phi_{2}-\phi_{1}\right)=\operatorname{sign}(\gamma)$. Let us now write:

$$
\frac{E\left(\pi_{1}\left(D_{11}^{*}\right)\right)}{E\left(\pi_{1}\left(D_{12}^{*}\right)\right)}=\frac{\phi_{1}\left(4 \gamma-2 \sqrt{2} \phi_{1}\right)^{2}}{\phi_{2}\left(4 \gamma-2 \sqrt{2} \phi_{2}\right)^{2}}=\varphi(\gamma)
$$

Figure ?? plots $\varphi(\gamma)$ for $\gamma \in(0,1)$. It shows that $\varphi(\gamma)$ is always smaller than one, indicating that profits are always higher with $D_{12}^{*}$.

Given that $E\left(\pi_{2}\left(D_{21}^{*}\right)\right)=E\left(\pi_{1}\left(D_{12}^{*}\right)\right)$ and $E\left(\pi_{1}\left(D_{11}^{*}\right)\right)=E\left(\pi_{2}\left(D_{22}^{*}\right)\right)$, it is always true that when $\gamma<0, \frac{E\left(\pi_{2}\left(D_{21}^{*}\right)\right)}{E\left(\pi_{2}\left(D_{22}^{*}\right)\right)}>1$ and that the borrower will always prefer $D_{21}^{*}$ over $D_{22}^{*}$. 
Figure 2: $\varphi(\gamma)=\frac{E\left(\pi_{1}\left(D_{11}^{*}\right)\right)}{E\left(\pi_{1}\left(D_{12}^{*}\right)\right)}$ for $\gamma \in(0,1)$. The figure shows that, for $\gamma>0, \varphi(\gamma)<1$. Therefore, the entrepreneur will always chooses $D_{12}^{*}$

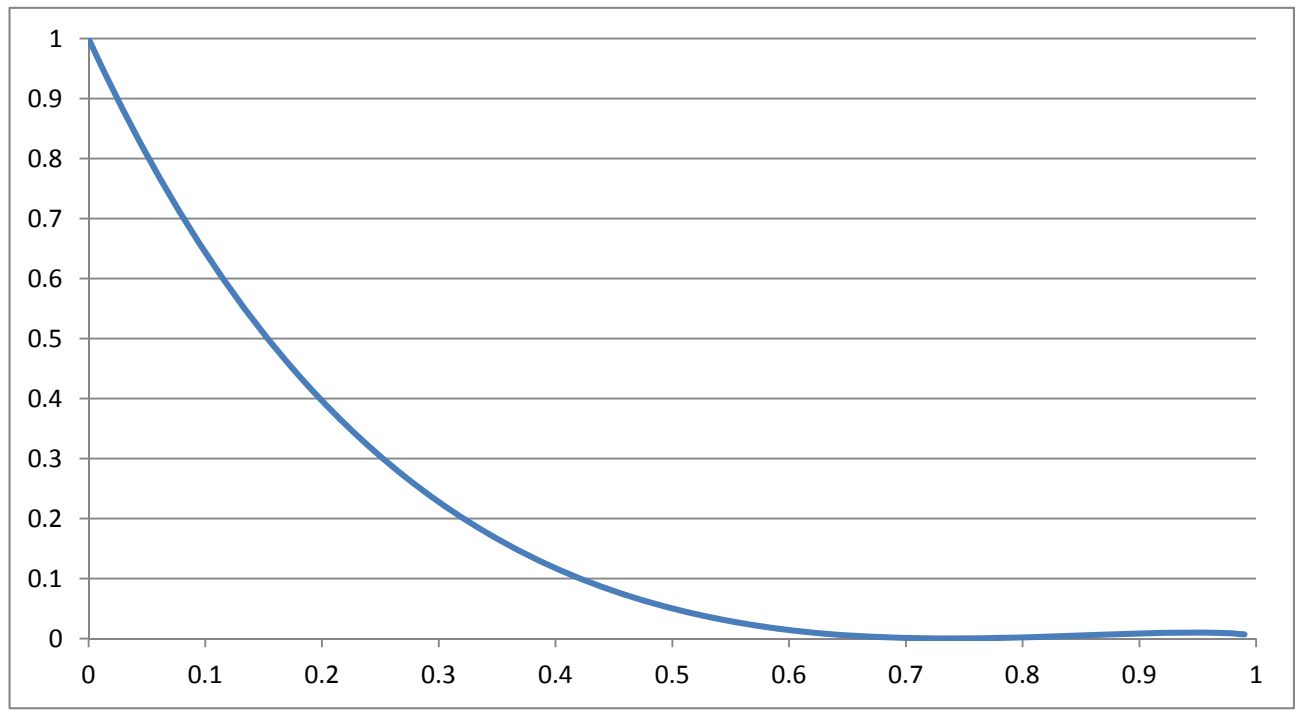

